\title{
Orthodontically Correction of A Class III Malocclusion without any Surgical Intervention in an adult Patient- $A$ Case report.
}

Rahman MM11, BDS, DDS, MCPS, FCPS and Hossain MZ², BDS, PhD.

ABSTRACT

Aim: A case of class-III malocclusion with a prognathic mandible is presented. Treatment objective included, improving facial aesthetics, correction of anterior and posterior cross bite, establishing a stable occlusion and masticatory efficiency.

Subject and Methods: The patient was a 17 years old girl who been classified as class-III malocclusion. Sequele included midface depress, anterior and posterior cross bite, reverse overbite $5.5 \mathrm{~mm}$ and reverse over jet $2.5 \mathrm{~mm}$, masticatory had efficiency, crowding in upper anterior segment. The aim was to flare out the maxillary arch and bring the maxillary anterior dentition over the lower dentition and established stable occlusion by class-III Activator and standard edge wise appliance.

Results: The anterior cross bite was corrected, with relative forward movement of point $-\mathrm{A}$. Case The profile of the patient was corrected and normal overbite and over jet established. A well balance lip profile was created and psychological impairment was eliminated.

Conclusion: Correction of anterior cross bite improved the facial, dental and profile of the patients. These factors contributed to the maintenance of a long term occlusal stability. (Bangladesh Journal of Orthodontics and Dentofacial Orthopedics, Vol. 2, No. 2, April 2012, p 38-40).

\section{HISTORY AND GENERAL CLINICAL BACKGROUND}

A female patient, 17 years old, came to department of orthodontics and dentofacial orthopedics in Dhaka Dental College Hospital, with orthodontics problem. Her complaint was mid face depress and in ability to incise properly. The patient was concerned about her midface problem and wanted orthodontics treatment to improve her present appearance and masticatory efficiency. The causes of the Class III malocclusion was unknown. Her mother reported that there were no hereditary Class III problem in her mothers family or in her father's family.

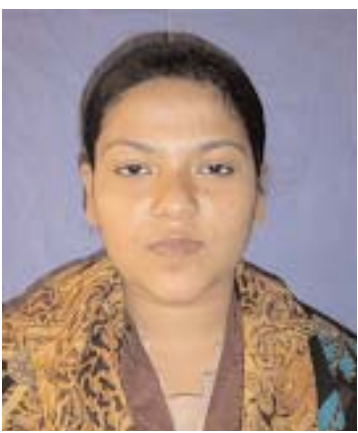

Fig-1: Frontal view.

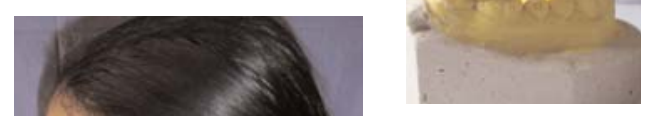

Fig-3(a)-Right molar relationship

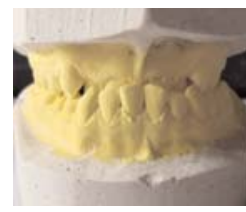

Fig-3(b)-Frontal view

TXMTIOT

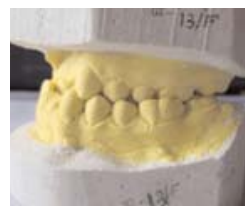

Fig-3(c)-Lefr molar relationship

\section{RADIOGRAPHIC EXAMINATION}

The orthopantomograph shows that there was no abnormality in tooth number, root form and alveolar bone. All of the wisdom teeth are absent. There was mild crowding in upper arches.

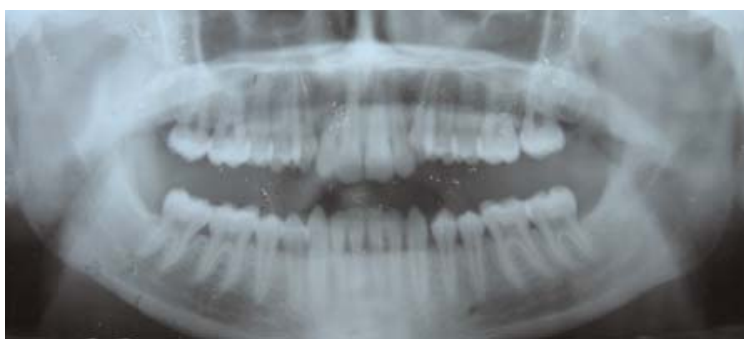

Fig-4; Orthopantomograph

\section{CLINICAL EXAMINATION}

Extra oral

Profile-concave type.

Facial divergent-anteriorly

Lip-Competent.

Nasolabial angle-obtuse.

Chin-prominent.

Fig-2: Profile view

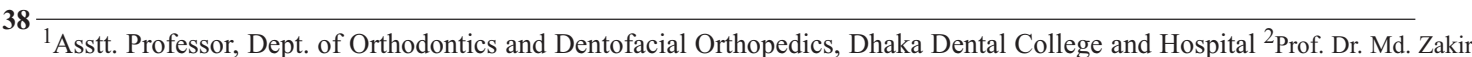
Hossain, Professor \& Head, Dept. of orthodontics, Dhaka Dental College
} 
Cephalometric Examination

Cephalometric analysis shows a skeletal dysplasia with mandibular prognathism (SNA angle is 83 degree, SNB angle is 90 degree and ANB angle is -7 degree). Upper and lower central incisor inclined lingually.

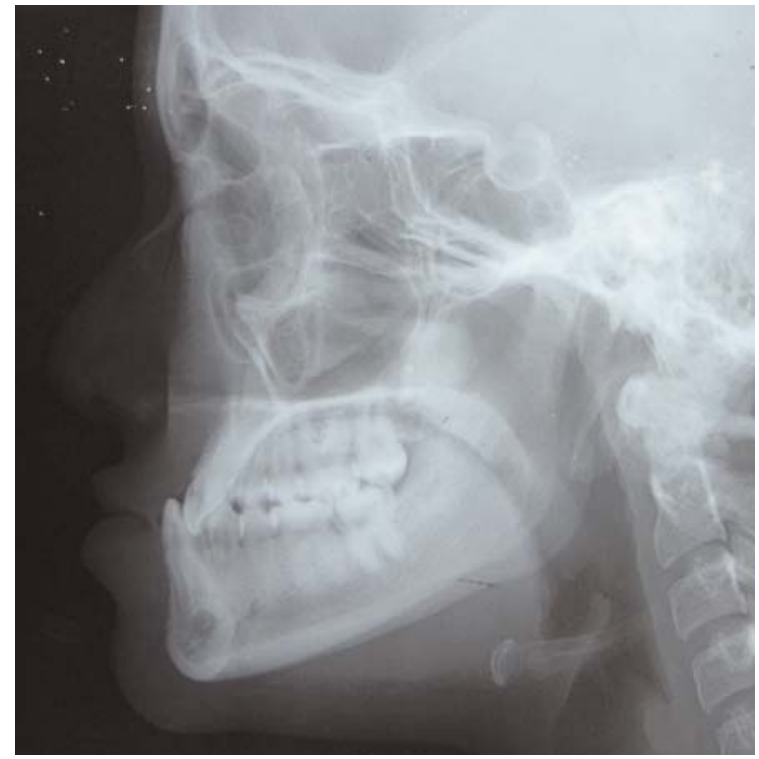

Fig-5; Lateral cephalograph.

\section{DIAGNOSIS}

The patient was diagnose with a skeletal and dental Class III malocclusion. The cast analysis revealed Class III molar and canine relationship both on right and left side. The posterior cross bite present on left side. The reverse overjet is $2.5 \mathrm{~mm}$ and reverse overbite is $5.5 \mathrm{~mm}$.

\section{TREATMENT OBJECTIVES}

- Correction of anterior and posterior cross bite.

- Correction of incisor relationship.

- Improvement of facial and dental aesthetic.

- Restoration of proper masticatory efficiency.

\section{TREATMENT PLAN}

- Step-I: Class III activator

- Step-II: Fixed appliance.

\section{TREATMENT PROGRESS}

The total active treatment period was 20 months.

Step-I: Although the age of the patient is not indicated for Class III activator, because growth of the patient is already completed. But functional analysis of the patient revealed that edge to edge relationship in incisor can achieved by Class III activators.
After 10 month treatment, edge to edge relationship of incisor is establish.

Step-II: Fixed appliance-The bracket were placed in the upper arch and the upper central and lateral incisors were moved labially by a standard edge wise appliance system.

\section{RESULT}

The overall all treatment of this patient is quite successful.

1. Dental change: Anterior cross bite was corrected. Normal over bite and over jet is established.

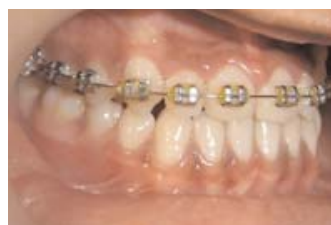

Fig-6(a); side view-RT,

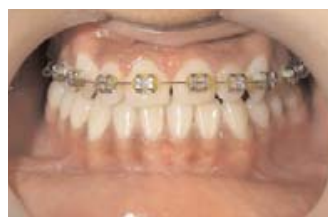

Fig-6(b) frontal view.

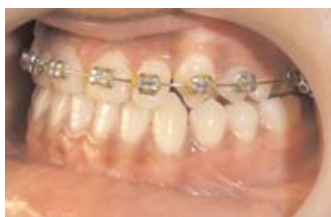

Fig-6(c): side view - Lt

\section{Profile change:}

Profile has been improved to before treatment. Chin protrusion has been improved

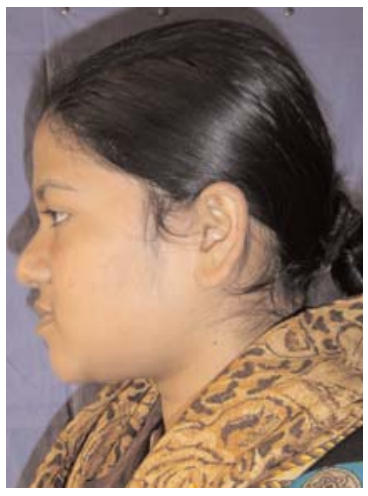

Fig-7: Before treatment.

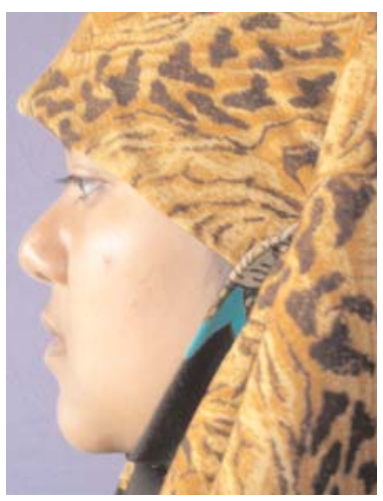

Fig-8: After treatment. 


\section{Cephalometric change:}

Cephalomertic changes has been occurs as compared to before treatment.

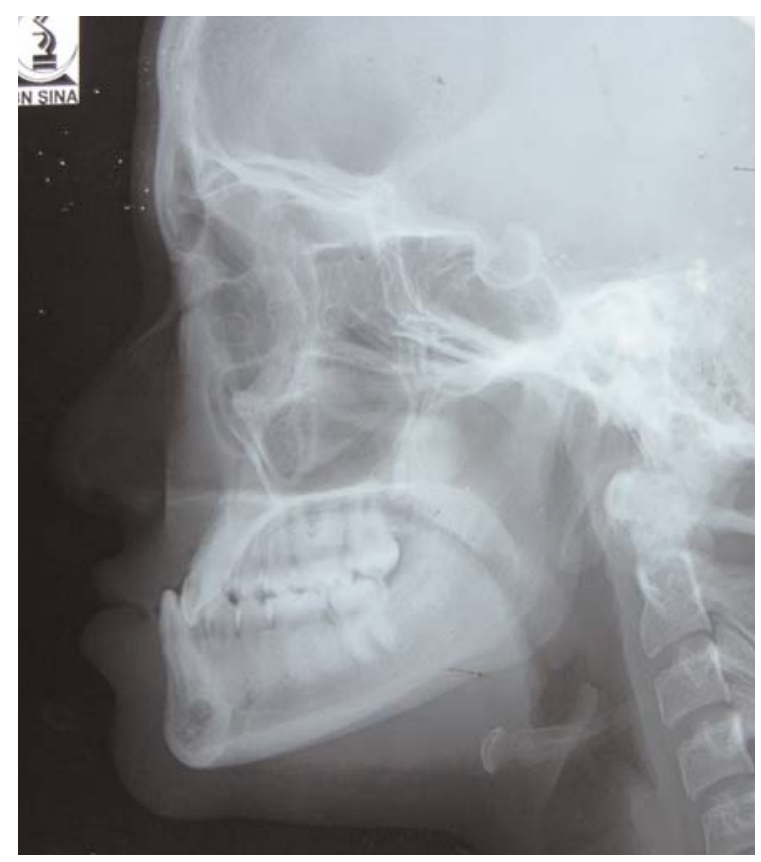

Fig-9a-Before treatment.

\section{Patients psychological changes:}

The patient and parent psychological satisfaction was achieved.

\section{CONCLUSION}

Skeletal pattern was camouflaged only by correction of the incisor relationship. Although over all facial, dental and occlusal changes were achieved satisfactorily. Patient aesthetic and functional (masticatory and incising) deficiency has been improved. The patient was very satisfied with the result of the treatment.

\section{REFERENEC:}

1. Gayle Glenn. The nonsurgical orthodontic correction of a Class III malocclusion. Am J- Orthod Dentofacorthp 1997;111:49-55.

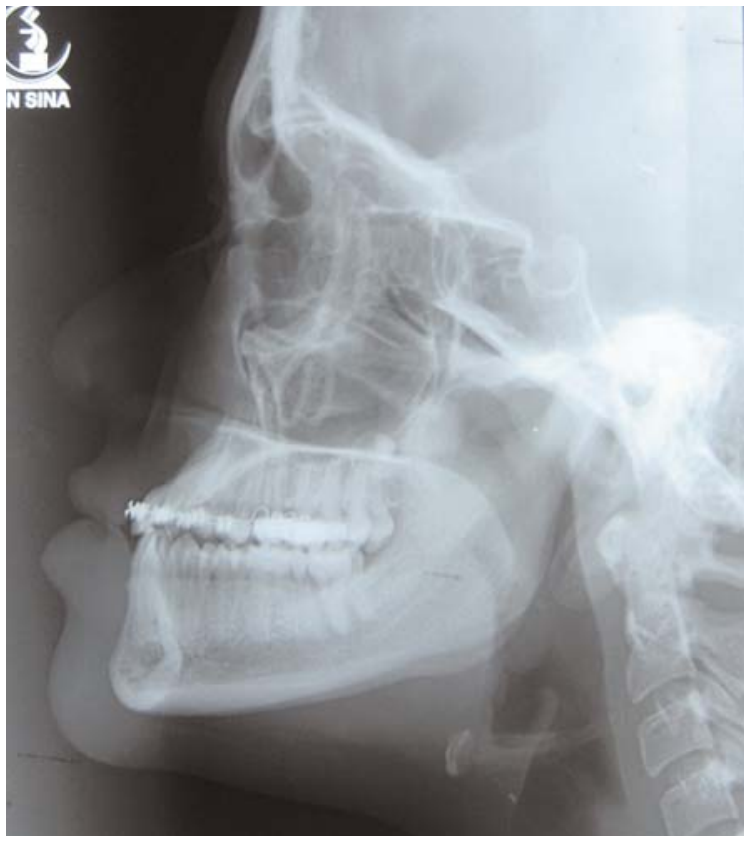

Fig-9b-After treatment.

2. John N . Fox, A non surgical and non extraction approach in the treatment of a skeletal and dental Class III malocclusion in a growing patient. AJO-1990; 98: 470-5.

3. Robert W. Baker, jr, J. Daniel Subteleny and Bejan Iranpour.Correction of a Class III mandibular prognathism abd asymmetry through orthodontics and orthognatic surgery. Am-Jorthod Dentofac orthop 1991;99:191-201.

4. M.Z. Hossain, Sabrina Hossain. Severe skeletal Class III malocclusion and open bite treated orthodontically without orthognatic surgery. Jof oral health. Vol-3. no.1 october- 1996.

\section{Correspondence}

Dr. Mohammad Muklesur Rahman BDS, FCPS

Asstt. Professor

Dept. of Orthodontics and Dentofacial Orthopedics

Dhaka Dental College and Hospital

Mirpur-14, Dhaka- 1206

Cell: +8801711379555, Email: mpino1971@yahoo.com 